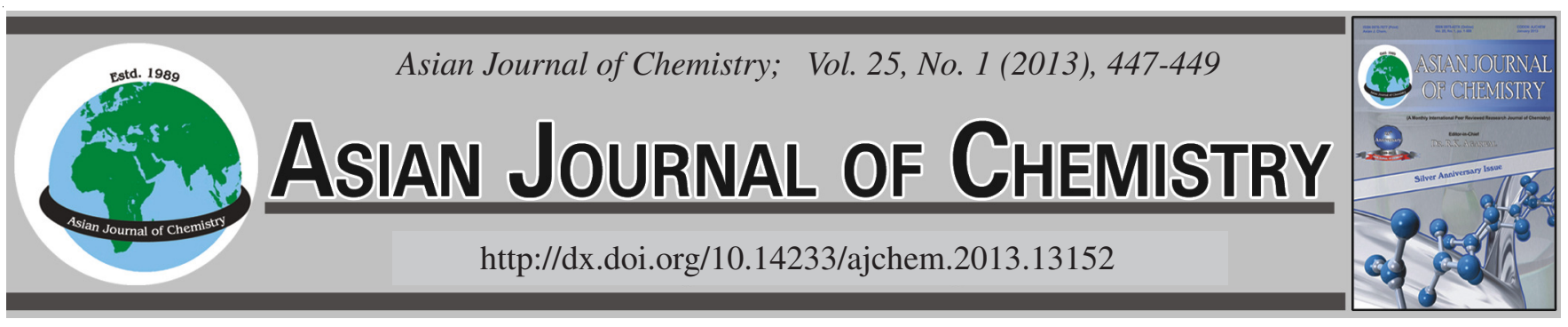

\title{
Preparation of Hybrid EA Coating with High Temperature Resistance for Fiber Bragg Grating Sensors
}

\author{
YANZI Yin, Jihui WANG*, Han Li, JiUXiaO Sun and Yundong Ji
}

School of Materials Science and Engineering, Wuhan University of Technology, Wuhan, P.R. China

*Corresponding author: Tel: +86 13971028120; E-mail: jhwang01@163.com

\begin{abstract}
In this paper, hybrid coating of EA and modified nano $\mathrm{SiO}_{2}$ was prepared for optical fibers. Systematic investigation especially heat performance testing, was carried on the hybrid coating. The results demonstrate that the performance of EA with $3 \%$ nano $\mathrm{SiO}_{2}$ was the best. From SEM images and XRD analysis, it can be concluded that amorphous nano- $\mathrm{SiO}_{2}$ was even distribution in EA. The tensile property, adhesion force, pencil hardness and glass temperature of EA coating can be improved by adding nano-SiO $\mathrm{S}_{2}$, while the thermal expansion coefficient was decreased. Fiber bragg grating sensors with $\mathrm{EA} / \mathrm{SiO}_{2}$ coating and $\mathrm{EA}$ were embedded in composites and processed under certain temperature and pressure, respectively. Comparing these two groups of data, results showed that modified coating could obviously decrease the hysteresis of fiber bragg grating sensor signals.
\end{abstract}

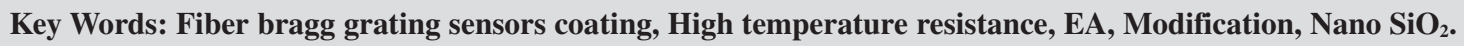

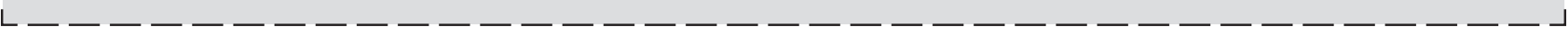

\section{INTRODUCTION}

Resin matrix composites were widely used in aircrafts. During flight and storage, composites were susceptible to damage. However, generally the damage cannot be visual found directly. With fiber bragg grating (FBG) sensors embedded in the materials, the non-destructive testing and real-time monitoring could be realized. The possible internal injury parts and damage degree of composite material could be timely monitored to improve the security and stability of the flight vehicle $^{1-8}$. However, the resin matrix composites used in the aircraft usually are carbon fiber composite materials. During molding process, the optical fiber coating would be detachment from fiber suffering high temperature and pressure ${ }^{9-11}$. The detachment may lead to serious problems for fiber grating sensor such as signal delay or loss. In this article, hybrid coating, which was composed of EA and modified nano-SiO $\mathrm{S}_{2}$ particles was proposed. Its properties were evaluated. For comparison, pure EA coating was also investigated.

\section{EXPERIMENTAL}

Modification of nano-SiO $\mathrm{Si}_{2}$ particles: 1) A certain amount of the particles were dried in oven for $2 \mathrm{~h}$; 2) Silane coupling agent of KH-550 ( $1 \%$ of nano- $\mathrm{SiO}_{2}$ quality, w/w) was diluted by 2-5 times of acetone; 3) The $\mathrm{SiO}_{2}$ was added in the solution of silane coupling agent and was mixed thoroughly, then they were agitated by an ultrasonicator for $1 \mathrm{~h}$; 4) The materials were dried in an oven till the acetone was evaporated completely.

Preparation of hybrid resin of EA-nano $\left.\mathrm{SiO}_{2}: 1\right)$ Modified nano- $\mathrm{SiO}_{2}$ particles $(1 \%, 2 \%, 3 \%, 4 \%, 5 \%$ of EA's weight) were added in the resin system of EA, TMPTA and TPGDA (EA: TMPTA: TPGDA = 55:30:15). The composites were fully mixed; 2) The possible bubbles in the mixture were eliminated under vacuum; 3) The resin was casted in the moulds and cured under the UV-lamp for $270 \mathrm{~s}$.

Testing method: Tensile strength, pencil hardness, glass transition temperature, adhesive force and thermal heat expansion coefficient of the coating were tested. Thin film tensile strength testing method was according to GB 1302291. Pencil hardness testing method was according to GB/T 6739-1996.

Since the optical fibers material is glass, adhesive force testing of fiber coating could be performed on glass plate. Testing method was according to GB9286-88.

\section{RESULTS AND DISCUSSION}

Basic properties of the coating: The basic properties of the coating were shown in Table-1.

From Table-1, with the increase in the content of inorganic nano- $\mathrm{SiO}_{2}$ particles, tensile strength, pensile hardness, adhesive force and glass transition temperature were increased firstly and then decreased. The top point was obtained at $3 \%$ weight 


\begin{tabular}{lcccccc}
\hline \multicolumn{7}{c}{ TABLE-1 } \\
BASIC PROPERTIES OF THE COATING \\
WITH DIFFERENT $\mathrm{SiO}_{2}$ CONTENTS \\
\hline $\mathrm{SiO}_{2}$ contents $(\%)$ & 0 & 1 & 2 & 3 & 4 & 5 \\
\hline Tensile strength $(\mathrm{MPa})$ & 11.65 & 17.49 & 20.88 & 23.24 & 20.48 & 19.25 \\
Pencil hardness & $2 \mathrm{H}$ & $2 \mathrm{H}$ & $3 \mathrm{H}$ & $4 \mathrm{H}$ & $4 \mathrm{H}$ & $4 \mathrm{H}$ \\
$\mathrm{T}_{\mathrm{g}}\left({ }^{\circ} \mathrm{C}\right)$ & 63.8 & 89.2 & 99.9 & 108.5 & 95.8 & 94.5 \\
Adhesive force & 2 & 2 & 1 & 1 & 1 & 2 \\
\hline
\end{tabular}

content of the nano particles. The phenomenon can be ascribed to the following reasons. The nano- $\mathrm{SiO}_{2}$ particles were inorganic rigid particles. After they were added into resin, the particles were combined with EA resin by physical adsorption or chemical reaction to strength the interface combination. As a result, the tensile strength of polymer could be enhanced. Since the specific surface area of the inorganic particles was larger and the binding force of the interface between particles and the resin matrix was bigger, the pencil hardness of coating was improved.

Since the nano- $\mathrm{SiO}_{2}$ was derivatized with epoxy groups, it can react with epoxy resin. Therefore, the glass transition temperature of the coating was increased. Above $3 \%$ of content of $\mathrm{SiO}_{2}$, the properties were decrease because that the excess nano-particles may randomly distributed within the resin, which may act as stress concentration points. So the performance of the coating was decreased.

Thermal properties of the hybrid coating: From Fig. 1 , it can be found that the EA added different contents of $\mathrm{SiO}_{2}$ lost it's weight slightly at about $300^{\circ} \mathrm{C}$. The main reason was that the solvent or unreacted monomer was evaporated. There was not large different on thermal decomposition temperature with different contents of $\mathrm{SiO}_{2}$. When the content was $3 \%$, the composites suddenly loss its weight quickly at $355.6^{\circ} \mathrm{C}$ because the rupture of main chain of $\mathrm{EA} / \mathrm{SiO}_{2}$. The thermo decompositon temperature of pure EA was $344^{\circ} \mathrm{C}$. Obviously, after being added with nano- $\mathrm{SiO}_{2}$ particles, the thermo decompose temperature of the coating was improved about $10^{\circ} \mathrm{C}$. It's shown that the nano- $\mathrm{SiO}_{2}$ particles have no apparent benefit to improve the thermal stability of EA.

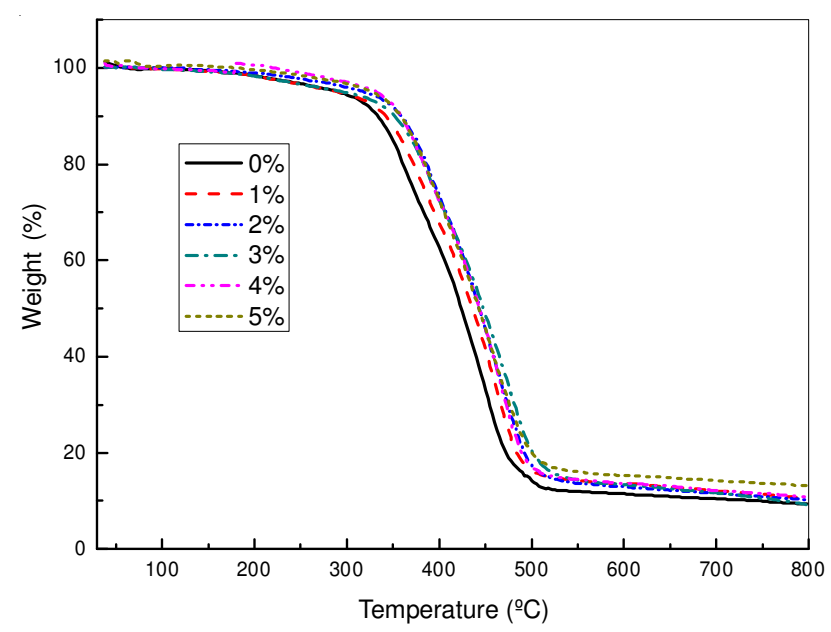

Fig. 1. TGA curves of different contents of $\mathrm{SiO}_{2}$ in $\mathrm{EA} / \mathrm{SiO}_{2}$

Because expansion coefficients of inorganic materials are generally low, lower thermal expansion coefficient of optical fiber coating could be expected by using the hybrid coating. Fig. 2. shows that, when the temperature was lower than glass transition temperature of $\mathrm{EA} / \mathrm{SiO}_{2}$, the linear thermal expansion coefficients of $\mathrm{EA} / \mathrm{SiO}_{2}$ with different contents $\mathrm{SiO}_{2}$ were similar. But at high temperature at which it was higher than glass transition temperature of $\mathrm{EA} / \mathrm{SiO}_{2}$, with increasing of weight content of the nano $\mathrm{SiO}_{2}$, the expansion coefficient decreased significantly. At high temperature, the resin was in high elastic state and the molecular chains could move freely, the expansion coefficient was larger. After being added with nano-particles, the expansion coefficient decreased because that crosslinking between nano-particles and resin would hinder the expansion of resin.

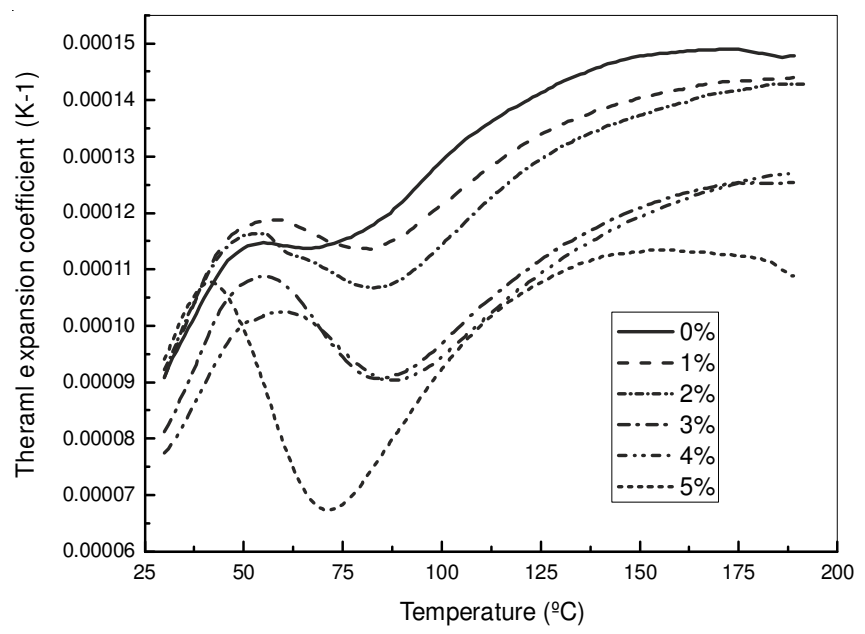

Fig. 2. Thermal expansion coefficient of $\mathrm{EA} / \mathrm{SiO}_{2}$ dispersing situation and states of nano- $\mathrm{SiO}_{2}$ in $\mathrm{EA}$

Fig. 3 showed that the SEM images of EA/SiO ${ }_{2}$ with $\mathrm{SiO}_{2}$ content of $1 \%, 3 \%, 5 \%$, respectively. When the content was $1 \%$, nano- $\mathrm{SiO}_{2}$ particles were smaller and homodispersed in the resin and reunion phenomenon was not obviously. With increasing of content of $\mathrm{SiO}_{2}$, the reunion particles were larger and the nano composites presented a kind of flake's fracture structure with rough surface. The reason was that the nano-

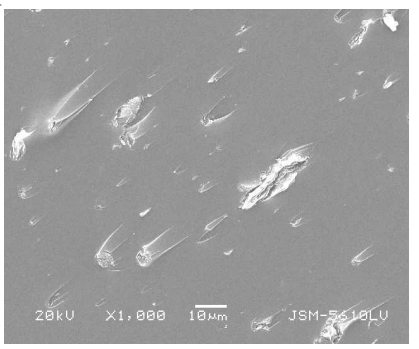

(a) $1 \% \mathrm{SiO}_{2}$

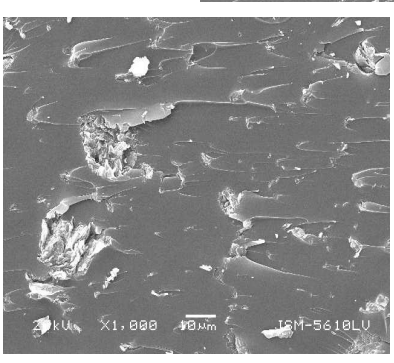

(c) $5 \% \mathrm{SiO}_{2}$

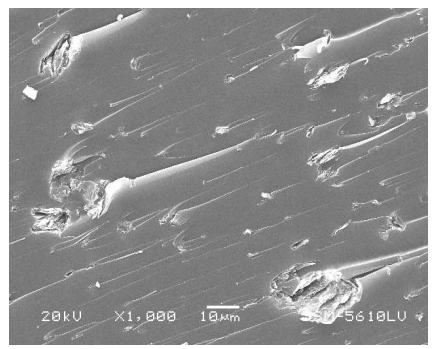

(b) $3 \% \mathrm{SiO}_{2}$

Fig. 3. Sections SEM figure of $\mathrm{EA} / \mathrm{SiO}_{2}$ 
$\mathrm{SiO}_{2}$ particles has larger specific surface area and more content would lead to increase the viscosity of the resin to hinder the dispersion of the particles.

Fig. 4 showed the XRD pattern of the coating. From Fig. 4 , in the range of $2 \theta$ was from $15^{\circ}$ to $30^{\circ}$, both $\mathrm{SiO}_{2}$ and EA/ $\mathrm{SiO}_{2}$ appeared the obvious diffraction peak. Both peaks were wide, overlapping peak. It indicated that there were no crystallization structures in these two materials. $\mathrm{SiO}_{2}$ treated after organic processing was in amorphous state, so it has no crystallization peak. That $\mathrm{EA} / \mathrm{SiO}_{2}$ also has amorphous peak indicated that $\mathrm{SiO}_{2}$ distributed in the EA matrix as amorphous state.

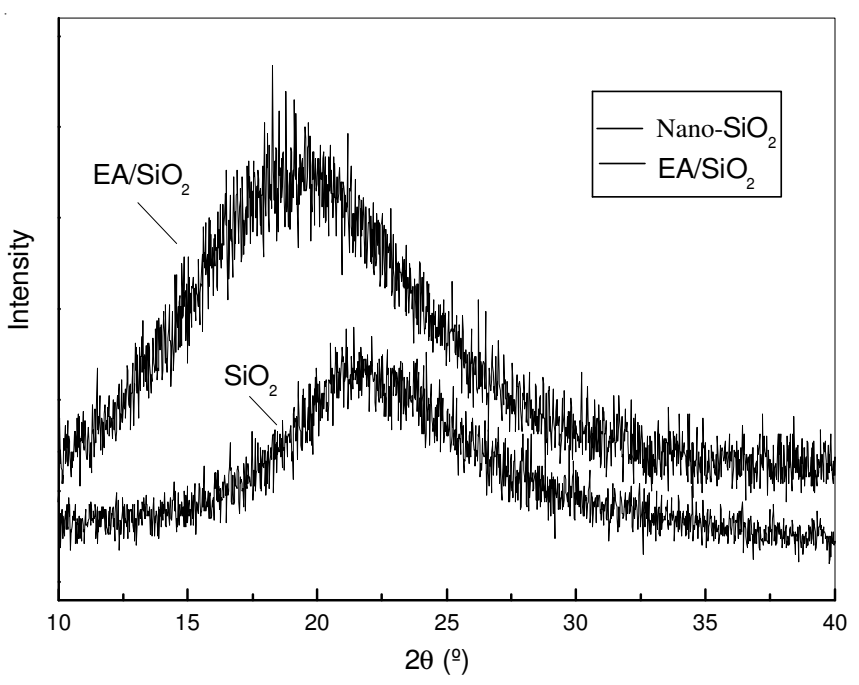

Fig. 4. XRD Analysis

Tensile performance of composites monitoring: Two different fiber bragg grating sensors were embedded in carbon/ epoxy composites. One of which was coated with EA and the other was coated with $3 \% \mathrm{SiO}_{2} / \mathrm{EA}$. Tensile test was carried out. Verification tendency of stress was contrast to wavelength. Verification of stress and wavelength was shown in Fig. 5. Results showed that change of wavelength got from fiber bragg grating with EA coatings lags of change of stress and curve of wavelength got from fiber bragg grating with $3 \% \mathrm{SiO}_{2} / \mathrm{EA}$ was consistent with the curve of stress.

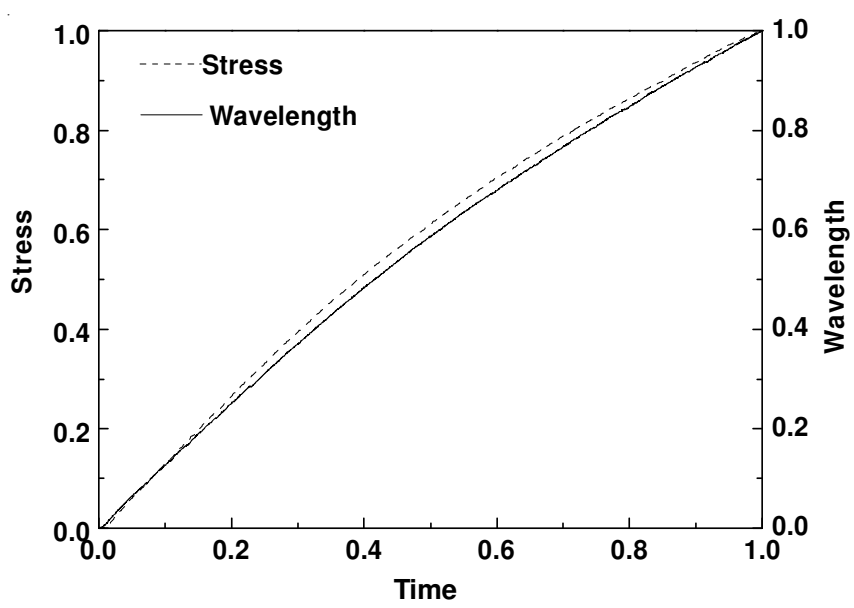

(a) EA

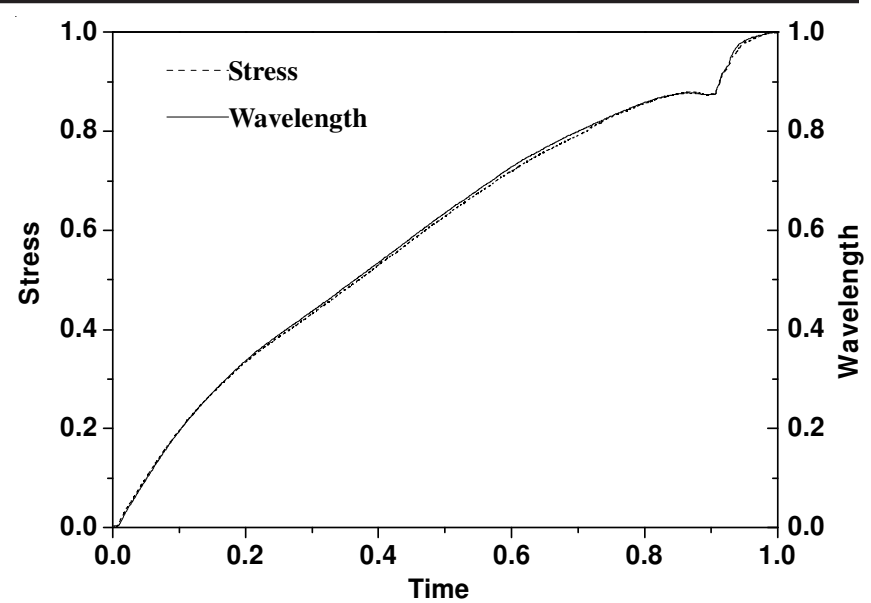

(b) $\mathrm{SiO}_{2} / \mathrm{EA}$

Fig. 5. Verification tendency of stress and wavelength

From above results and discussion, when the content of nano- $\mathrm{SiO}_{2}$ was $3 \%$, the properties of coating was significantly improved and it could be as promising coating of fiber bragg grating sensors embedded in resin matrix composites under high temperature molding formation for nondestructive testing.

\section{Conclusion}

$3 \%$ Weight content of modified nano- $\mathrm{SiO}_{2}$ particles were added into EA. After physical blended, the nano- $\mathrm{SiO}_{2}$ particles exist in EA as amorphous state. The thermal properties, tensile strength, pencil hardness, adhesive force of modified EA were all improved, which can be applied as coating of fiber bragg grating sensors embedded in resin matrix composites under high temperature molding formation for nondestructive testing. This kind of coating could improve sensitivity of fiber bragg grating sensors.

\section{REFERENCES}

1. K.T.V. Grattan and T. Sun, Sens. Actuators A, 82, 40 (2000)

2. R. de Oliveira, S.L. and R. Chatton, Composites: Part A, 39, 1083 (2008).

3. A.R. Chambers, M.C. Mowlem and L. Dokos, Compos. Sci. Technol., 67, 1235 (2007).

4. H.-C. Lin, S.-T. Shiue and Y.-M. Chou, Surf. Coat. Technol., 202, 5360 (2008).

5. S.-S. Chen and S.-T. Shiue, Optical Fiber Technol., 12, 268 (2006).

6. J. Shiue, M.J.M., P.R. Stupak and V.V. Rondinella, Acta Mater, 54, 2631 (2006).

7. U.-Y. Zhang, G.W. and I.W. Boyd, Appl. Surf. Sci., 186, 568 (2002).

8. N.K. Pandey and B.C. Yadav, Sens. Actuators A, 128, 33 (2006).

9. C.S. Li, M.S. Cao and R.G. Wang, Compos. Sci. Technol., 63, 1749 (2003).

10. J.A. Greene, T.A. Tran and V. Bhatia, Smart Mater. Struct., 4, 93 (1995).

11. S. Takeda, Y. Okabe and N. Takeda, Composites: Part A, 33, 971 (2002). 